\title{
Correction to: Effect of Microstructures on the Anisotropy of the Roll Casting Strip of Cold Rolled 3003 Aluminum Alloy
}

Canpei Ding, Gecheng Yuan, Haibin Guo, Zhiyong Long and Qian Yuan

\section{Correction to:}

Chapter "Effect of Microstructures on the Anisotropy of the Roll Casting Strip of Cold Rolled 3003 Aluminum Alloy" in: Y. Han (ed.), Physics and Engineering of Metallic Materials, Springer Proceedings in Physics 217, https://doi.org/10.1007/978-981-13-5944-6_62

The original version of this chapter was inadvertently published with incorrect grant number in the acknowledgement section. The grant number of Guangzhou Science and Technology Project of China has been changed from 2015110010034 to 201510010034. 